\title{
'My Fitbit Thinks I Can Do Better!' Do Health Promoting Wearable Technologies Support Personal Autonomy?
}

\author{
John Owens ${ }^{1}$ (D) Alan Cribb ${ }^{1}$
}

Received: 17 March 2017 / Accepted: 25 May 2017 / Published online: 6 June 2017

(C) The Author(s) 2017. This article is an open access publication

\begin{abstract}
This paper critically examines the extent to which health promoting wearable technologies can provide people with greater autonomy over their health. These devices are frequently presented as a means of expanding the possibilities people have for making healthier decisions and living healthier lives. We accept that by collecting, monitoring, analysing and displaying biomedical data, and by helping to underpin motivation, wearable technologies can support autonomy over health. However, we argue that their contribution in this regard is limited and that - even with respect to their 'autonomy enhancing' potential- these devices may deliver costs as well as benefits. We proceed by rehearsing the distinction that can be drawn between procedural autonomy (which refers to processes of psychological deliberation) and substantiverelational autonomy (which refers to the opportunities people have for exercising potential actions). While the information provided by wearable technologies may support deliberation and decision-making, in isolation these technologies do little to provide substantive opportunities to act and achieve better health. As a consequence, wearable technologies risk generating burdens of anxiety and stigma for their users and reproducing existing health inequalities. We then reexamine the extent to which wearable technologies actually support autonomous deliberation. We argue that wearable technologies that subject their users to biomedical and consumerist epistemologies, norms and values also risk undermining processes of genuinely autonomous deliberation.
\end{abstract}

Keywords Autonomy $\cdot$ Ethics $\cdot$ Health $\cdot$ Procedural $\cdot$ Relational $\cdot$ Self-tracking Substantive $\cdot$ Technology $\cdot$ Wearable

Proposed paper for Philosophy and Technology - Special Issue on Ethics of Biomedical Data Analytics

John Owens

john.owens@kcl.ac.uk

1 Centre for Public Policy Research, Faculty of Social Science \& Public Policy, King's College London, Waterloo Bridge Wing, Franklin-Wilkins Building, Waterloo Rd, London SE1 9NH, UK 


\section{Introduction}

This paper engages with some of the ethical questions regarding autonomy posed by the proliferation of what we shall call 'health promoting wearable technologies'. For the purpose of this paper, these are defined as digital self-tracking devices designed to improve the health, fitness and well-being of their users by collecting, analysing and displaying biomedical data. These technologies are often presented as a means of expanding the possibilities their users have for making healthier decisions and living healthier lives. Central to their appeal is the claim that the information and motivation they provide will grant people greater autonomy over their health, enabling people to become fitter, healthier and happier. We draw on a combination of ethical and social theory to subject this claim to critical scrutiny.

The term 'health promoting wearable technologies' could be taken to refer to a long and diverse list of items - spectacles, false teeth, prosthetic limbs, pace-makers, hearing aids or even a sturdy pair of walking boots. But we are using it in a more restrictive sense. In particular, we have in mind the spectrum of discrete, mobile digital devices (hardware) and the various programmes, apps and interactive bots (software) that have been developed to enable people to monitor, collect, analyse and display biomedical data. Popular examples of such wearable technologies include fitness bands dedicated to tracking health and fitness, more versatile smartphones, smart watches and assorted devices integrated into clothing, footwear and jewellery made by companies like Apple, Fitbit, Google, Hexoskin, Jawbone, Misfit, Nike, Ringly and Samsung. These devices support thousands of apps and bots, popular examples of which include Apple Health, Calorie Counter, Endomondo, Forksy, Google Fit, Heart Analyzer, Lifesum and Strava.

Health promoting wearable technologies are becoming increasingly popular. According to Morgan (2016), we are witnessing the proliferation of mobile and wearable technologies globally for the purpose of tracking and monitoring health, fitness and well-being. As of 2014, 45.8 million American smartphone owners were reported to have used a fitness and/or health app (Nielsen 2014), while Fitbit alone is reported to have sold over 23 million devices in the 2015-2016 financial year in over 65 countries worldwide (Fitbit 2017b). Uptake in these technologies is anticipated to continue to grow as technologies evolve and consumer demand rises (Martin 2015).

The paper begins by considering how health promoting wearable technologies might support health-related autonomy. We then subject this idea to critical analysis through two interlinked arguments. Firstly, we rehearse the distinction that can be drawn between procedural autonomy (which refers to processes of psychological deliberation) and substantive-relational autonomy (which refers to the genuine opportunities people have for action). We argue that while wearable technologies may provide information that supports processes of autonomous decision-making over health, on their own these technologies do little to provide their users with genuine opportunities for autonomous action. Secondly, we raise some concerns about the effects of wearable technologies on autonomous deliberation. We argue that where wearable technologies incorporate the biomedical and commercial epistemologies, norms and values of their manufacturers, they may compromise processes of autonomous deliberation. We therefore conclude that wearable technologies are limited in how far they can enhance their users' autonomy over health, and that their effects on autonomy may include costs as well as benefits. 


\title{
2 Wearable Technologies and Enhanced Autonomy over Health
}

Lupton's (2016) work on the 'quantified self' leads a nascent scholarship that critically engages with the development of wearable technologies. An important element of this emerging work will be scrutiny of the ways in which wearable technologies are presented in popular and commercial discourses. Central to the growing appeal of health promoting wearable technologies is their promise to enable people to take greater control over their health through access to biomedical data that was previously unavailable. For example, Fitbit, a leading manufacturer of health and fitness trackers, presents itself in this way:

'Fitbit motivates you to reach your health and fitness goals by tracking your activity, exercise, sleep, weight and more'. (Fitbit 2017a)

Key to what is at stake in the presentation of these devices is the notion that they provide ways of enabling and empowering their users to 'reach their health and fitness goals'. This appeal is dramatically represented in the following vision for health promoting wearable technologies presented by Lauren Constantini, chief executive of health technology company Prima Temp Incorporated, at the TEDxMileHigh conference in 2014:

\begin{abstract}
'What might be possible if you could learn from the data your body is radiating how to make the most of your body and your mind? What would you do with that power? Well the age of the quantified self is upon us! Self-knowledge through self-tracking... by looking over time at our good days and bad days... we can identify the events and manipulate our environment to make us more happy and less sad and more productive... Not only can we become healthier and more productive we can become better parents, better caretakers, better lovers, better humans... We all hear that we are only using about $10 \%$ of our human capabilities, so our future selves can be ten-fold better than our current selves... And this indicates humanity with potentially enhanced natural capabilities... What might be possible if you could use techology to expand your opportunities and abilities to be human beyond what you thought was possible?' (Constantini 2014)
\end{abstract}

It would be unwise to read too much into the sales pitch of an enthusiastic entrepreneur with a firm interest in the growth of health promoting wearable technologies. However, this statement is illustrative of the wider discourses that frequently characterise these devices as a platform for enabling and empowering human beings to new levels of performance and achievement. Particularly instructive for our purposes is Constantini's suggestion that the data these devices provide will offer their users new powers and enhanced capabilities. This claim is underwritten by the assumption that users of these technologies will be able (and will wish) to act on the information provided, by manipulating their environments, thereby taking on new roles and identities which are 'ten fold better' than their current ones. These claims amount to the 
promise that users of wearable technologies will have greater autonomy over their health, fitness and well-being.

Autonomy is a theme that runs deeply through contemporary cultural attitudes towards health and policy trends surrounding health promotion. People are increasingly expecting, and being expected, to be able to contribute positively to, and accept personal responsibility for, their own health and well-being (Waller 2005). Respect and support for personal autonomy has become a key plank of contemporary health promotion discourse and strategy and has been facilitated by a combination of measures based on enhancing public education, motivation, supporting choice and encouraging patients and the wider public to actively 'coproduce' good health outcomes for themselves (Owens 2012; Owens and Cribb 2013). Wearable technologies fit squarely within these trends as a means of informing and enabling individuals' choices and facilitating forms of direct participation in caring for their own health. These technologies promise to dismantle the traditional asymmetry of information that has characterised clinical relationships where the public rely on expert medical professionals to collect, monitor and interpret their health data. Having direct access to biomedical data is presented as a means of empowering people by making them aware of the state of their body and enabling them to directly self-monitor their habits and behaviour.

One important dimension to note is the role that psychological motivation linked to goal setting and fulfilment plays in processes of empowering users of these technologies to greater autonomy over health. We saw above that Fitbit presents itself as a tool for motivating people to achieve their health and fitness goals. Samsung presents the 'Endomondo Premium' app for its smartphones and watches in similar terms:

'Using GPS tracking, it logs and monitors your activities, like running, swimming, cycling or even canoeing. You can set personal goals, better understand your progress, and be inspired to achieve your fitness goals'. (Samsung 2017)

By collecting, monitoring, analysing and displaying information and then providing advice, prompts, encouragement and recommendations, these devices appear able to guide, motivate and inspire their users towards realising their specified health and fitness goals.

We do not doubt that in many cases health promoting wearable technologies can provide effective support for people seeking to improve their health and fitness. However, we believe that any suggestion that these technologies support their users' autonomy over health needs to be critically examined and qualified. To undertake this critical examination, we first distinguish between different senses of autonomy.

\section{Procedural Autonomy over Health}

Questions about the nature of autonomy are a central concern within ethics, and particularly so within healthcare ethics and bioethics. Important contributions to the debate about autonomy have been made by theorists from across a broad range of disciplinary traditions and ideological perspectives. To cut through this complexity, we 
rehearse a distinction that can be drawn between two important versions of autonomy: a 'procedural' definition that has been highly influential within analytic philosophy and a 'substantive-relational' definition that emerges from feminist ethics and contemporary social theory.

Procedural accounts of autonomy have emerged from within the analytic tradition of philosophy, where autonomy has been characterised as relating to the cognitive processes involved in an individual's decision-making. The influential liberal account of procedural autonomy is strongly associated with the personal capacity for selfgovernance and the ability to take decisions about one's own life independently and without external support, interference or constraint. Accordingly, procedural accounts of autonomy have tended to emphasise the importance of freedom of will and the capacity to engage in processes of independent deliberation about the course of one's life. The stress placed on independent psychological deliberation means procedural accounts employ a cognitive criteria for establishing the extent to which a person can be said to be autonomous. That is, it is concerned with establishing whether or not a person has undergone, or possesses the capacity for undergoing, the requisite psychological processes to be deemed autonomous. Frankfurt (1989) has provided the most influential account of procedural autonomy based on critical reflection and the ordering and endorsement of desires. Frankfurt's account suggests that personal autonomy consists in the capacity to act in line with one's genuine and authentic volitions.

Procedural accounts of autonomy suggest that what is important is not the contents of the desires someone has or the consequences of the decisions they make, but the reasoning behind these desires and decisions. So long as a person goes through the necessary cognitive processes, they can be deemed autonomous. These accounts therefore place a strong emphasis on the importance of protecting deliberative procedures from external interference or corrupting influences. Such concerns can be widely recognised in discussions surrounding processes of consent and competency. Where someone is unable to critically reflect, order and/or endorse a set of preferencesperhaps because they lack the cognitive capacity to do so, because they do not have the requite information, or if they are subject to some form of external interference- they are deemed unable to exercise autonomy. On this reading, autonomy with respect to health means being free to deliberate over and make decisions about one's health. For example, this might mean that a person is able to reflectively weigh up information and then freely decide whether or not to change their diet, quit smoking or take up a new exercise regime. Here, the key thing is their ability to make independent and informed decisions via processes of critical reflection and endorsement.

What does this procedural account mean for evaluation of the claim that wearable technologies are able to enhance their users' autonomy over health? By providing access to biomedical data and generating awareness of habits, behaviours and performances, there is good reason to think these technologies can support processes of deliberation about health that enhance their users' procedural autonomy. For example, information about one's heart rate, sleeping patterns, mobility or calorific intake might help people make important decisions that directly affect their health. Moreover, if these devices are also able to offer encouragement, motivation and inspiration, they may help people cultivate and reinforce self-control and intentional habits of mind and behaviour that are more in line with their endorsed and genuine volitions. This may 
lead to healthier behaviour, whether through a better diet, more consistent compliance with medical regimes or increased physical exercise. The comedian and essayist David Sedaris vividly illustrates the potential of wearable technologies to support motivation and increased physical activity through his experience of using a Fitbit:

'the Fitbit is a digital trainer, perpetually egging us on. During the first few weeks that I had it, I'd return to my hotel at the end of the day, and when I discovered that I'd taken a total of, say, twelve thousand steps, I'd go out for another three thousand'.

'But why?' Hugh asked when I told him about it. 'Why isn't twelve thousand enough?'

'Because', I told him, 'my Fitbit thinks I can do better'. (Sedaris 2014)

If Sedaris's genuine desire is to improve his health through increased physical activity, his Fitbit appears to be supporting his autonomy by helping him to meet his goal of taking more steps each day. In many cases, the data and motivational prompts provided by wearable technologies appear able to positively support the deliberations and decisions people make about their health, and may provide the motivation and encouragement to support them to reach the goals they set for themselves. We will return to consider this provisional conclusion in more detail later on, but prima facie there seems good reason to think that wearable technologies can support procedural autonomy over health.

\section{Substantive-Relational Autonomy over Health}

A more sceptical assessment of the potential for wearable technologies to support their users autonomy over health is provided by a broader notion of autonomy, referred to as a substantive-relational account (Mackenzie 2008; Owens and Cribb 2013). From this broader view, a focus on processes of cognitive deliberation appears to be relatively narrow in scope: procedural accounts only tell us part of the story about what autonomy is, why it is important and how it can and should be promoted. While they may provide important details about how people have arrived at a particular decision, procedural accounts tell us little about what people can actually do to enact that decision. We have argued elsewhere that it is important to understand autonomy in terms of the opportunities people have for free and meaningful action (Owens and Cribb 2013). Indeed, it is people's capacity to act and achieve the goals they have decided upon that is often considered morally and politically salient about autonomy, and we noted above that it is a promise of supporting action towards health and fitness goals that provides a major selling point of these devices.

The substantive-relational account of autonomy we have in mind has been derived from scholarship in feminist ethics, notably writings about relational autonomy (Mackenzie 2008; Mackenzie and Stoljar 2000). These relational accounts were partly developed out of a concern to facilitate 'real-world' understanding of the practices of 
autonomous decision-making by paying close attention to the ways in which a person's circumstances may influence their deliberative processes. In particular, relational accounts of autonomy pay attention to the ways in which a person's deliberative processes will be subject to the myriad influences of socialisation. While there is no definitive account of relational autonomy-i.e. it is a label that permits a variety of interpretations - its proponents have stressed the need to recognise the social embeddedness of persons and the causal role that structural circumstances have on people's capacity to engage in processes of autonomous deliberation (Westlund 2009). It is possible to refer to a spectrum of positions derived from the literature on relational autonomy. For instance, so-called procedural-relational accounts of autonomy acknowledge the importance of socialisation on decision-making but retain the view that autonomy is essentially a cognitive process bound up with deliberation, albeit one that must be made answerable to 'public reasoning' (Ben-Ishai 2012; Benson 2000). For the purposes of our argument, we set such intermediate positions aside and concentrate on those perspectives that depart more radically from procedural accounts of autonomy.

Substantive-relational accounts of autonomy broaden the notion of autonomy beyond processes of cognitive deliberation to include the possibilities for autonomous action (Mackenzie 2008; Oshana 2006). Such accounts consider a narrow focus on procedures of autonomous deliberation as a necessary but insufficient condition for any account of autonomy that can usefully be applied to evaluate real-life situations, behaviours and practices. Accordingly, substantive-relational accounts extend the concept of autonomy beyond the cognitive domain and into the realm of material and social structures and relationships. They suggest that attention to the impact that a person's structural circumstances should not end with consideration of their capacity for autonomous deliberation, rather it should also include the substantive opportunities they have to enact the decisions they have made and actually achieve their intended goals.

It is important to note that shifting attention from autonomous deliberation to autonomous action involves altering the conceptual focus of the idea of autonomy, from deciding to acting. This is significant because acting appears to be a far more complicated activity than deciding: action involves engaging with the myriad types of antecedent material and social structures that shape the potential actions available to a person, as well as considering how the consequences of these actions will affect their future opportunities. For example, while procedural accounts may consider a person who weighs up the information from their wearable device and then freely decides to take up a new diet or exercise regime to be autonomous on the basis that they have engaged in independent cognitive processes of deliberation, a substantive-relational account would ask additional questions about whether they are in a position to successfully enact their decision. For example, if the person lacks the money, time, space and/or confidence required to cook healthier food or go to the gym regularly, the substantive-relational account could conclude that the person lacked the capacity for autonomous action.

Substantive-relational accounts of autonomy therefore suggest we must pay attention to more than just the cognitive processes by which decisions are made: we must consider the conditions, contents and consequences of a person's decisions, the circumstances in which these decisions are made and the implications these decisions have for their intended actions. A person's capacity for autonomous action is therefore 
shaped by the variety, quality and quantity of opportunities that their material and social environment makes available to them, as well as by the extent to which they are willing and able to exploit these opportunities. On this basis, promoting a person's substantiverelational autonomy involves providing them with supportive circumstances and relationships that confer on them genuine opportunities to enact their decisions.

This shift to a substantive-relational view of autonomy is significant for our consideration of health promoting wearable technologies because there are good reasons to be sceptical about any claims that providers of these technologies make about them offering people genuine opportunities to meet the health and fitness goals they set for themselves. Health promoting wearable technologies may enable people to improve their health by supplying information and encouragement, but they do little to change a person's capacity to act in the world and to positively enhance their opportunities for achieving better health. Given that people's opportunities to achieve better health in practice are always mediated by their wider material and social circumstances, then those people who are relatively wellpositioned may already enjoy circumstances that enable them to act on the information or prompt provided by their device (e.g. if they are wealthy, confident, have positive and supportive familial and clinical relationships, have access to required goods, commodities and facilities, etc.). However, for those people in less-advantageous social positions (particularly those affected by oppressive conditions linked to isolation, exclusion, poverty, deprivation or discrimination), simply being informed or encouraged that a particular form of action will help them to meet their health and fitness goals may not make much, if any, difference.

Providing people with genuine opportunities to act on the information and encouragement provided by their devices (and to exercise autonomous action over their health) will often require attending to the adverse material and social circumstances that constrain their potential actions. This argument is borne out by the extensive literature that provides evidence of the causal role that material, economic and social factors have in creating patterns of health inequalities across society (Dorling 2013; Marmot 2010, 2015; Marmot and Wilkinson 2005; Pickett and Wilkinson 2015). These social epidemiological studies clearly demonstrate that the social determinants of health - the conditions in which people are born, grow, live, work and age, and the ways in which these conditions are affected by the relative distribution of money, resources, power, recognition and status - create patterns of unequal health across society. As Marmot explains, 'the lower a person's social position, the worse his or her health' (2010: p. 9). Personal autonomy over health, understood in substantiverelational terms as the genuine opportunities or capabilities people have to act to sustain and/or improve their health, is substantially shaped by these social determinants (Abel and Frohlich 2010; Owens and Cribb 2013; Prah Ruger 2010; Sen 1992;).

Wearable technologies are, of course, narrowly concerned with measuring, analysing and displaying the biomedical data of their users, and not with the wider structural contexts that shape their health and fitness. As Lupton explains,

'many digitized health promotion strategies focus on individual responsibility for health and fail to recognise the social, cultural and political dimensions of digital technology use'. (2014: p. 1) 
Without engaging with the broader structural conditions that cause patterns of unequal health status, there seems to be little reason to expect that health promoting wearable technologies will do anything other than reproduce, reinforce or even widen entrenched patterns of health inequalities. Moreover, this recognition that opportunities for autonomous action over health are socially mediated is important for understanding associated concerns that health promoting wearable technologies may generate forms of anxiety for their users, particularly if they find themselves unable to act to in line with the information or advice provided. For relatively advantaged people who may only lack the will power or motivation to improve their health, a wearable device may provide the positive and supporting presence they need. But for people living in adverse material and social circumstances, the presence of a device that informs them that they have a potential health risk or fitness problem that they are unable to fix may be a significant cause of concern and frustration. For these people, an inability to act in accordance with the information and prompts provided and to achieve their health and fitness goals may lead to the development of anxiety, stigma and a form of self-victim blaming (Crawford 1977). By providing a constant stream of information about alarming biomedical data, unhealthy habits and the seemingly unobtainable targets they are failing to meet, such technologies may erode their users' (perhaps fragile) sense of control over their health, not to mention their feelings of self-esteem and wellbeing.

The doubts we have rehearsed here resonate with some published professional concerns and empirical literature. As Spence, a GP from Glasgow, suggests,

'We must reflect on what we might lose here, rather than what we might gain. Will apps simply empower patients to overdiagnosis and anxiety?' (Husain and Spence 2015: p. 2)

A further concern relates to studies which have indicated that there is a lack of evidence demonstrating that wearable technologies actually do enable people to improve their health in practice. For example, following randomised control trials conducted with young adults seeking to reduce obesity, Jakicic and colleagues claimed that 'devices that monitor and provide feedback on physical activity may not offer an advantage over standard behavioral weight loss approaches' (2016: p 1161). Similarly, Spence has questioned the efficacy of wearable devices to deliver improvements in health. He describes apps and devices as 'untested', 'unscientific' and 'likely useless' (Husain and Spence 2015: p. 2). Moreover, he raises concerns that promises that these devices will enable their users to achieve better health may end up being an illusion:

'death and disease is a lottery outside our control. So when the "undeserving" sick get sick, they feel cheated. These new technologies will serve only to fuel this anger and resentment further'. (Husain and Spence 2015: pp. 2-3)

It may be suggested that highlighting health promoting wearable technologies' limits when it comes to supporting autonomous action is unnecessary: Is it not just unreasonable to expect wearable technologies to be able to make the deep structural changes 
required for gains in substantive-relational autonomy? Perhaps so, however, we would argue it is important to highlight these limits because, as we have seen, the rhetoric that presents wearable technologies characterises them as devices that will support autonomous action by enabling their users to do more, to be more and to actually achieve their health and fitness goals. It is precisely the distinction between procedural and substantive-relational autonomy that helps to critically unpick this rhetoric.

\section{Reconsidering Wearable Technologies and Procedural Autonomy}

We now return to the suggestion that health promoting wearable technologies support processes of deliberative autonomy over health. As we have noted, a good case can be made for this assertion. People's autonomous deliberation can be supported by external factors including by support from and dialogue with other actors, and wearable technologies can be seen as 'non-human actors' (Latour 2005) capable of supporting the motivation of users and with whom users are in 'dialogue'. This is reflected in Sedaris' characterisation of his Fitbit as a personal trainer spurring him on to do better. To the extent that we can validly claim that the 'voice' of the relevant technology is in broad alignment with (and responsive to) what Frankfurt (1989) sees as the users' genuine higher-order desires - the voice and intrinsic motivations of our 'better selves' - then the claim for the autonomy enhancing potential of wearable technology seems strong. However, for a human actor (e.g. a health professional or personal trainer) to support another actor's procedural autonomy is a highly skilled and dilemma-laden practice (Cribb and Entwistle 2011), and this suggests that there are grounds to be sceptical about the capacity of a 'non-human actor' to achieve this same feat and to negotiate the same balancing acts. In what remains of the article, we raise concerns that these technologies may not necessarily align with, or be responsive to, users' genuine volitions in a straightforward or consistent way. Wearable technologies are products of wider biomedical and consumerist cultures that frequently issue imperatives around health and fitness decisions. As such, many of these devices appear to embody and reinforce particular epistemologies, values and norms. It is therefore important to question the extent to which health promoting wearable technologies can be thought of as supporting processes of autonomous deliberation.

Health promoting wearable technologies sit within a wider group of health promotion strategies that use 'behaviour change techniques' to encourage people to take healthier decisions and actions. A well-known example of such approaches is the 'nudge' theory developed by Thaler and Sunstein (2008). This describes how insights from behavioural economics and so-called choice architecture can be deployed to subtly manipulate people's environments in order to make them more likely to make particular choices. The paradigmatic example of nudge strategy in action is the benevolent and health-conscious canteen manager who repositions the fruit ahead of the chocolate cake on the counter so that their employees are more likely to choose a healthy option. While no choices have been removed from employees - the cake remains available - the change in the canteen environment makes it more likely that employees will behave in the way the management wishes. Here, the emphasis is on using forms of 'soft power' in the name of 'liberal-paternalism': people's ability to make decisions for themselves is preserved, but the intervention makes them more 
likely to decide according to some external set of values or objectives. Nudge techniques have been particularly effective where health promotion campaigns have focussed on achieving behaviour change by influencing lifestyle choices. For example, high-profile public health programmes in the UK have seen the introduction of food labelling, health warnings on cigarettes and alcohol and the introduction of 'Change4life' and 'This Girl Can' exercise campaigns. Each of these might be thought to boost procedural autonomy by providing information about and encouragement for healthier decisions. However, they are also crafted with the intention of interfering with people's decisions and altering their behaviour. Rather than providing health information in a neutral and balanced manner, these campaigns aim to produce perlocutionary effects in people that encourage particular outcomes to be adopted. It is possible to read the strategic intent behind such campaigns and to witness the way in which the norms and values of biomedicine are being promoted through them as an example of 'systematically distorted communication' (Habermas 1970).

Health promoting wearable technologies can be viewed in the same light. As Bakici and Sanches suggest, 'Information and communication technologies are not valueneutral tools that reflect reality; they privilege some forms of action, and they limit others' (2014: p. 399). The ways in which they display and communicate information means health promoting wearable technologies can operate as an advanced form of the nudge strategy - as devices 'programmed' to improve health through influencing decisions and altering habits and behaviour.

Generally speaking, no one is forced to use health promoting wearable technologies, (although increasingly health insurance companies like Vitality and Optima Health are rewarding their customers for doing so (Olson 2014) and there is a growing trend for corporations to use activity trackers to promote the health and well-being of their employees (Till 2014)). ${ }^{1}$ However, whether adopted voluntarily or otherwise, health promoting wearable technologies cannot be seen as simply embodying or supporting the autonomy of users. Many health promoting wearable technologies are designed to encourage users to subscribe to particular norms and values and conform to specific behaviours and practices. This might take an overt form through the issuing of instructions and/or commands. For example, smart watches that monitor and display their users' heart rates will announce when it is 'Time to stand!', while diet apps monitor the number of calories consumed per day and prescribe a cap on further consumption. Even more radically, Forksy is an app designed to promote healthy eating by 'calling you out on your guilty pleasures and even have your friends monitor what you eat and comment on poor choices' (Yao 2016). These devices' use of nearpunitive measures like peer pressure and social condemnation are intended to influence

\footnotetext{
${ }^{1}$ A detailed analysis of insurers' use of activity tracking technologies will have to wait for another occasion, but it is worth briefly considering here the potential impact such schemes may have on peoples' deliberative autonomy. For example, some health insurers invite their customers to record exercise activity using fitness tracking devices to earn 'activity points' which will lower the cost of the insurance plan. In such cases, it is worth considering if customers sign up to these plans because they support their intrinsic desires for improved health or whether people end up reluctantly exercising for the sake of an extrinsic financial incentive. Where the latter occurs, concerns that these schemes may negatively affect people's deliberative autonomy seem credible. For more on this discussion, see Ashcroft's (2011) analysis of the impact that financial incentives may have on personal autonomy.
} 
the decisions that their users make. At the same time, they often reinforce positive behaviour by issuing reward notifications and awards for activities, and may also integrate with social media to generate competition between users to encourage greater performance. Such technologies promote what Brockling (2016) describes as an 'entrepreneurialism of the self': by internalising the narrative of competitive selfimprovement and the associated consequences of success and failure, users of wearable technologies become the subject of powerful self-governance regimes.

In similar terms, these technologies can be viewed as introducing regimes of neoliberal governmentality that turn individuals into 'subjects of responsibility, autonomy and choice... [and require individuals] to act upon them through shaping and utilizing their freedom' (Rose 1999: p. 54). Again, Sedaris' experience of using a Fitbit provides a helpful illustration of the power of these devices to contribute to (extreme) narratives of self-improvement:

'I look back on the days I averaged only thirty thousand steps, and think, Honestly, how lazy can you get? When I hit thirty-five thousand steps a day, Fitbit sent me an e-badge, and then one for forty thousand, and forty-five thousand. Now I'm up to sixty thousand, which is twenty-five and a half miles'. (Sedaris 2014)

The influence of health promoting wearable technologies is also often reinforced through covert means. Perhaps unsurprisingly, devices that monitor and analyse biomedical data employ biomedical terminology and epistemologies to frame their prompts and instructions. Motivational prompts, advice and commands concerning biomedical data - e.g. regarding blood pressure, calories consumed, heart rate - derive authority from being delivered using the technical 'voice of medicine' reinforced by the associated weight of expert knowledge (Barry et al. 2001). Moreover, in a systematic review of the literature, Morgan reports that digital health technologies tend to be "focused on compliance and the construction of "health threats"' (2016: p. 10). By framing the data they produce in biomedical terms, these devices may act as a conduit for the colonisation of the user's lifeworld (Habermas 1984), extending the reach of medicalisation (Illich 1990) and reinforcing the view that the user's health is subject to risks that can be best mitigated through submission to professional diagnosis and instruction. ${ }^{2}$ Meanwhile, well-being and fitness performance-hours slept, steps taken, miles run, etc.- are given additional gravity by a 'regime of numbers' and the possibilities for unequivocal evaluation offered by the analysis of quantitative metrics (Rose 1991).

The manipulative potential of these health promoting wearable technologies can be reinforced by their place within wider consumerist cultures which supply strong signals and messages that may further compromise users' procedural autonomy. These devices are produced by large and often opaque and unaccountable technology corporations that play an increasingly influential role in shaping people's attitudes, beliefs and preferences (Bernal 2014). The issues of individual privacy and manipulation

\footnotetext{
${ }^{2}$ For a more substantial discussion of the potential risks of personal health monitoring devices colonising the lifeworlds of their users, see Mittelstadt et al. 2014.
} 
resulting from corporate use of big data are also of obvious relevance to concerns about the influences of health promoting wearable technologies (Mittelstadt and Floridi 2016). These devices also appear as 'enhancing technologies': products of a health and beauty industry that uses the significant power of advertising to seek to achieve preconceived goals and ideals (Elliot 2003). Particularly significant is the potential these devices have for influencing the decisions and behaviours of their users by encouraging them to internalise the perfectionist values and norms propagated by their manufacturers. Much of the advertising employed in health and beauty serves to manipulate the emotions of consumers, using the seductive language of hope, desire, empowerment and success backed up with messages of fear, guilt and shame. As Spence says:

'health and fitness have become the new social currency, spawning a "worried well" generation. Health "bling" is everywhere: all things Lycra, T shirts from exotic charity half marathons, the chatter of personal trainers and training programmes, and bikes that cost more than cars. Even food is no longer to be enjoyed: it has become a pharmacopoeia of blended pulses, green leaves, and nuts. Now, in many ways this is a great improvement on the drinking, smoking, corned beef eating generation that came before. But our technologically advanced society is avoidant, fearful, insecure, and worried about anything and everything. We have an unhealthily health obsessed generation who will seize on these new health apps and devices... A Wild West approach to development is playing out and will use the advertising classic - fear-to sell products. War, pestilence, and famine are all out to grass; technology, medicine, and over-diagnosis are the new riders of the Apocalypse' (Husain and Spence 2015: pp. 2-3)

Through the careful manipulation of emotions, health promoting wearable technologies can submit their users to regimes of performative instruction and evaluation. To the extent that they are successful, these devices fit Rose's description of 'technologies of subjectivity... that enable strategies of power to infiltrate the interstices of the human soul' (1999: p. 8). In doing so, they may often suggest there is only one possible decision to make: be healthier!

Thus, wearable technologies do more than just monitor, collect, analyse and display biomedical data. They serve other purposes - and evaluating their contribution to their users' autonomy depends entirely on understanding where these purposes come from and how they are embodied and promoted by the technologies. Such devices can support users' deliberative processes, but they can also interrupt, influence and undermine them, and hence their contribution to supporting procedural autonomy should be questioned. Once again, this point is illustrated neatly by Sedaris' encounters with a wearable device. After losing control, he asks:

'Why is it some people can manage a thing like a Fitbit, while others go off the rails and allow it to rule, and perhaps even ruin, their lives?... my Fitbit died. I was devastated when I tapped the broadest part of it and the little dots failed to appear. Then I felt a great sense of freedom. It seemed that my life was now my 
own again. But was it? Walking twenty-five miles, or even running up the stairs and back, suddenly seemed pointless, since, without the steps being counted and registered, what use were they? I lasted five hours before I ordered a replacement, express delivery. It arrived the following afternoon, and my hands shook as I tore open the box. Ten minutes later, my new master strapped securely around my left wrist, I was out the door, racing, practically running, to make up for lost time'. (Sedaris 2014)

\section{Conclusion}

This paper has critically examined the claim that health promoting wearable technologies can support the autonomy that their users have over health through the monitoring, collection, analysis and communication of biomedical data. We accept that there is a case for thinking that the information and prompts provided by these devices can support processes of procedural autonomy through facilitating deliberation and decision-making. In some cases, these devices may also support users' capacity for autonomous action, for example, through underpinning forms of motivation or habit formation. However, we have suggested that these claims should be subject to critical scrutiny, and that the potential of these technologies to support both autonomous deliberation and autonomous action is limited in significant ways.

We have argued that health promoting wearable technologies have greater potential to support processes of autonomous deliberation than they do capacities for autonomous action. This is significant since it is the genuine opportunities that people have to act and to achieve their goals that is often considered morally and politically important. Certainly, much of the appeal of health promoting wearable technologies stems from their presentation as devices that will enable people to actually improve their health and meet their fitness goals. We suggest that the limitations of these technologies to support their users' substantive-relational autonomy over health is worth emphasising, especially because these devices risk reproducing existing health inequalities across society and creating additional burdens of anxiety and stigma.

We have also raised concerns about the potential for health promoting wearable technologies to undermine their users' deliberative and decision-making procedures. Many of these devices are products of powerful biomedical and commercial corporations with their own interests and agendas. Where these technologies reflect and reproduce biomedical and commercial epistemologies, values and norms, especially where these are not closely aligned with their users' considered and ordered desires and rely on manipulative techniques, they may significantly disrupt processes of free and independent judgement, and thus may significantly undermine procedural autonomy. For these reasons, we conclude that the autonomy enhancing potential of health promoting wearable technologies is limited and carries risks and harms as well as benefits. Wear with care!

Acknowledgements We would like to thank the Brocher Foundation for hosting, Becky Brown, Luna Dolezal and Heather Morgan for organising and all attendees of the 'Vice and Virtue: the Rise of Self-Tracking Technologies and the Moralising of "Health" Behaviours' conference in Geneva, May 2016. Alan Cribb is a Professorial Fellow at the Health Foundation and is grateful for the associated funding. 
Open Access This article is distributed under the terms of the Creative Commons Attribution 4.0 International License (http://creativecommons.org/licenses/by/4.0/), which permits unrestricted use, distribution, and reproduction in any medium, provided you give appropriate credit to the original author(s) and the source, provide a link to the Creative Commons license, and indicate if changes were made.

\section{References}

Abel, T., \& Frohlich, K. (2010). Capitals and capabilities: linking structure and agency to reduce health inequalities. Social Science \& Medicine, 74, 236-244.

Ashcroft, R. (2011). Personal financial incentives in health promotion: where do they fit in an ethic of autonomy? Health Expectations, 14, 191-200.

Barry, C., Stevenson, F., Britten, N., Barber, N., \& Brady, C. (2001). Giving voice to the lifeworld. More humane, more effective medical care? A qualitative study of doctor-patient communication in general practice. Social Science \& Medicine, 53, 487-505.

Ben-Ishai, E. (2012). Fostering autonomy: a theory of citizenship, the state and social service delivery. University Park, PA: Penn State University Press.

Benson, P. (2000). Feminist intuitions and the normative substance of autonomy. In C. Mackenzie \& N. Stoljar (Eds.), Relational autonomy: feminist perspectives on autonomy, agency and the social self (pp. 124 142). Oxford: Oxford University Press.

Bernal, P. (2014). Internet privacy rights. Cambridge: Cambridge University Press.

Brockling, U. (2016). The entrepreneurial self. London: Sage.

Cakici, B., \& Sanches, P. (2014). Detecting the visible: the discursive construction of health threats in a syndromic surveillance system design. Societies, 4(3), 399-413.

Constantini, L. (2014). Wearable tech expands human potential. Speech at TEDxMileHigh. Available online: https://www.youtube.com/watch?v=FESv2CgyJag

Cribb, A. and Entwistle, V.A. (2011). Shared decision making: trade-offs between narrower and broader conceptions. Health Expectations, 14(2), 210-219.

Dorling, D. (2013). Unequal health:t scandal of our times. Bristol: The Policy Press.

Elliot, C. (2003). Better than well: American medicine meets the American dream. New York: W. W. Norton \& Co..

Fitbit. (2017a). Official site for activity trackers and more. Available online: https://www.fitbit.com/uk

Fitbit. (2017b). Press release: Fitbit reports \$574M Q416 and \$2.17B FY16 revenue, sells 6.5M devices in Q416 and 22.3M devices in FY16. Available online: https://investor.fitbit.com/press/press-releases/pressrelease-details/2017/Fitbit-Reports-574M-Q416-and-217B-FY16-Revenue-Sells-65M-devices-in-Q416and-223M-devices-in-FY16/default.aspx

Frankfurt, H. (1989). Freedom of the will and the concept of the person. In J. Christman (Ed.), The inner citadel: essays on individual autonomy (pp. 63-76). New York: Oxford University Press.

Habermas, J. (1970). On systematically distorted communication. Inquiry: An Interdisciplinary Journal of Philosophy. doi:10.1080/00201747008601590.

Habermas, J. (1984). The theory of communicative action: reason and the rationalization of society (Vol. 1). London: Heinemann.

Husain, I., \& Spence, D. (2015). Can healthy people benefit from health apps? British Medical Journal. doi:10.1136/bmj.h1887.

Illich, I. (1990). Limits to medicine-medical nemesis: the expropriation of health. London: Penguin.

Jakicic, J., Davis, K., Rogers, R., King, W., Marcus, M., Helsel, D., Rickman, A., Wahed, A., \& Belle, S. (2016). Effect of wearable technology combined with a lifestyle intervention on long-term weight loss: the IDEA randomized clinical trial. Journal of the American Medical Association., 316(11), 1161-1171.

Latour, B. (2005). Reassembling the social: an introduction to actor-network theory. Oxford: Oxford University Press.

Lupton, D. (2014). Apps as Artefacts: Towards a Critical Perspective on Mobile Health and Medical Apps. Societies. doi:10.3390/soc4040606.

Lupton, D. (2016). The quantified self. Cambridge: Polity Press.

Mackenzie, C. (2008). Relational autonomy, normative authority and perfectionism. Journal of Social Philosophy, 39, 512-533.

Mackenzie, C., \& Stoljar, N. (Eds.). (2000). Relational autonomy: feminist perspectives on autonomy, agency and the social self. Oxford: Oxford University Press. 
Marmot, M. (2010). Fair society, health lives: the Marmot review. Available online: http://www. instituteofhealthequity.org/

Marmot, M. (2015). The health gap: the challenge of an unequal world. London: Bloomsbury Press.

Marmot, M., \& Wilkinson, R. (2005). Social determinants of health (2nd ed.). Oxford: Oxford University Press.

Martin, J. (2015). 13 wearable tech trends to watch in 2016. Available online: http://www.cio. com/article/3017995/wearable-technology/13-wearable-tech-trends-to-watch-in-2016.html.

Mittelstadt, B., \& Floridi, L. (2016). The ethics of big data: current and foreseeable issues in biomedical contexts. Science and Engineering Ethics, 22, 303. doi:10.1007/s11948-015-9652-2.

Mittelstadt, B., Fairweather, B., Shaw, M., \& McBride, N. (2014). The ethical implications of personal health monitoring. International Journal of Technoethics, 5(2), 37-60.

Morgan, H. (2016). 'Pushed' self-tracking using digital technologies for chronic health condition management: a critical interpretive synthesis. Digital Health, 2, 1-41.

Nielsen. (2014). How consumers are using tech to stay healthy. Available online: http://www.nielsen. com/us/en/insights/news/2014/ihealth-how-consumers-are-using-tech-to-stay-healthy.html

Olson, P. (2014). Wearable tech is plugging into health insurance. Forbes. Available online: https://www. forbes.com/sites/parmyolson/2014/06/19/wearable-tech-health-insurance/\#60e4788518bd

Oshana, M. (2006). Personal autonomy in society. Aldershot: Ashgate.

Owens, J. (2012). Creating an impersonal NHS? personalization, choice and the erosion of intimacy. Health Expectations, doi:10.1111/hex.12000.

Owens, J. and Cribb, A. (2013). Beyond choice and individualism: understanding autonomy for public health ethics. Public Health Ethics, 6(3), 262-271.

Pickett, K., \& Wilkinson, R. (2015). Income inequality and health: a causal review. Social Science \& Medicine, 128, 316-326.

Prah Ruger, J. (2010). Health capability: conceptualization and operationalization. American Journal of Public Health, 100(1), 41-49.

Rose, N. (1991). Governing by numbers: figuring out democracy. Accounting, Organizations and Society, 16(7), 673-692.

Rose, N. (1999). Governing the soul: shaping of the private self (Second ed.). London: Free Associations Books.

Samsung. (2017). Get in shape with Samsung health and fitness. Available online: http://www.samsung. com/uk/discover/mobile/get-in-shape-with-samsung-health-and-fitness/

Sedaris, D. (2014). Stepping out. The New Yorker. Available online at: http://www.newyorker. com/magazine/2014/06/30/stepping-out-3

Sen, A. (1992). Inequality reexamined. Oxford: Clarendon Press.

Till, C. (2014). Exercise as labour: quantified self and the transformation of exercise into labour. Societies. doi: $10.3390 /$ soc 4030446.

Thaler, R., \& Sunstein, C. (2008). Nudge: improving decisions about health, wealth and happiness. New Haven: Yale University Press.

Waller, B. (2005). Responsibility and health. Cambridge Quarterly of Healthcare Ethics, 14, 177-188.

Westlund, A. (2009). Rethinking relational autonomy. Hypatia, 24, 26-49.

Yao, M. (2016). Top 5 Bots To Get You Fit. Available online: http://www.topbots.com/top-5-best-fitness-botsfitness-apps/. 